\title{
Predictability and stability of refraction with increasing optical zone diameter in hyperopic LASIK
}

This article was published in the following Dove Press journal:

Clinical Ophthalmology

8 May 2010

Number of times this article has been viewed

\author{
Mostafa A El-Helw \\ Ahmed M Emarah \\ Cairo University, Cairo, Egypt
}

Correspondence: Mostafa El-Helw Cairo University, 52 Manyal Street, Manyal, Cairo, I I 45 I, Egypt

Tel +l I 20I 01228920

Fax + I I 20I 27474858

Email helw@yahoo.com
Objective: We undertook a prospective nonrandomized study to assess refractive outcome and patient satisfaction with hyperopic laser in situ keratomileusis (LASIK) using variable optical zone diameters in correction of hyperopia of more than 4.00 diopters.

Methods: Fourteen adults (comprising 28 hyperopic eyes) underwent hyperopic LASIK correction for hyperopia of more than 4.00 diopters. The sample was divided into two groups. Group 1 included the right eyes of the 14 patients who underwent hyperopic LASIK using a $6.5 \mathrm{~mm}$ optical zone diameter. Group 2 comprised the left eyes of the same patients with the only difference being that the optical zone diameter was $6.0 \mathrm{~mm}$.

Results: The mean age of the patients was $36.42 \pm 5.10$ years. Group 1 eyes had a median (range) preoperative uncorrected visual acuity (UCVA) of $0.79(0.52)$ and best-corrected visual acuity (BCVA) of $0.15(0.08)$. Group 2 had a median preoperative UCVA of $0.79(0.60)$ and BCVA of 0.15 (0.08). The median postoperative UCVA in Group 1 was $0.17(0.21)$ and BCVA was $0.15(0.13)$. In Group 2, the median postoperative UCVA was $0.30(0.32)$ and BCVA was $0.15(0.26)$. Group 1 had a median preoperative refraction of $+5.37(1.75)$ diopters and the median postoperative refraction at one week was $-0.23(1.25)$ diopters, at three months was $+0.75(0.75)$ diopters, and at six months was +0.75 (1.00) diopters. Group 2 had a median preoperative refraction of $+5.00(1.75)$ diopters, and the median postoperative refraction at one week was $+0.13(1.5)$ diopters, at three months was $+1.00(0.75)$ diopters and at six months +1.25 (1.25) diopters. The difference was statistically significant between groups 1 and 2 . The difference within each group was also significant. Group 1 eyes were stabilizing after the threemonth period in contrast with Group 2 in which the refractive changes continued throughout the follow-up period.

Conclusion: Larger optical zone diameter in correction of hyperopia of more than 4.00 diopters was more predictable, stable and safe.

Keywords: hyperopia, LASIK, optical zone, refraction

\section{Introduction}

Surgical correction of hyperopia remains a great challenge. Several techniques including automated lamellar keratoplasty, holmium-YAG laser thermal keratoplasty, photorefractive keratectomy, conductive keratoplasty, clear lens extraction, and phakic intraocular lens implantation have been used and clinically evaluated in recent years, but none of them are completely satisfactory. Hyperopic laser in situ keratomileusis (H-LASIK) has been frequently used. However, the visual outcome of H-LASIK is not as favorable as for myopic LASIK. H-LASIK is performed according to its Food and Drug Administration (FDA) approval to correct hyperopia up to +6.00 diopters of spherical equivalent. ${ }^{1}$ The 
hyperopic treatment consists of an annular zone of ablation that causes a relative flattening of the corneal periphery and a concomitant relative steepening of its center. Enlarging the optical zone diameter theoretically will reduce the incidence of postoperative glare and halos. Larger outer zones may provide for less regression of the refractive effect. ${ }^{2}$

This study was carried out simultaneously in both eyes of the same group of patients, with a unified set of parameters, with the optical zone being the only variable. The aim was to determine if enlarging the optical zone provides for less regression of the refractive effect.

\section{Methods}

This was a prospective, nonrandomized analysis carried out on both eyes of the same group of patients using the Mel 80 Laser system. The research followed the tenets of the Declaration of Helsinki. Informed consent was obtained from all patients after details of the procedure were explained, with emphasis on the intended outcome. The El-Nour Eye Hospital ethical committee approved the project.

The study was performed in 28 hyperopic eyes of 14 adults, comprising 11 females and three males, of mean age $36.43 \pm 5.11$ (range 29-45) years, with spherical equivalent refraction of more than +4.00 diopters. Inclusion criteria were bilateral hyperopia $>+4.00$ diopters, with the difference in best-corrected visual acuity (BCVA) between the two eyes being not more than two lines using the Snellen's decimal visual acuity test, to exclude cases of anisometropic amblyopia. Exclusion criteria were central keratometric values $>45.00$ diopters and pachymetry of $<500 \mu$. Patients with a pupillary diameter $>6 \mathrm{~mm}$ (mesopic range) were also excluded. Patients with general contraindications for LASIK surgery, including autoimmune diseases, diabetes, pregnancy, and ocular diseases including glaucoma, cataract, retinal diseases, and dry eye, were not considered as candidates. Patients were asked to stop wearing their contact lenses for two weeks before their study assessment.

Right eyes were assigned to have an optical zone diameter of $6.50 \mathrm{~mm}$ (Group 1), while left eyes of the same patients had an optical zone of $6.00 \mathrm{~mm}$ diameter (Group 2). In Group 1 the median (range) preoperative refraction was +5.37 (1.75) diopters and the median preoperative uncorrected visual acuity (UCVA) was 0.79 (0.52) and BCVA was 0.15 (0.08). In Group 2, median preoperative refraction was +5.00 (1.75) diopters, and the median preoperative UCVA $0.79(0.60)$ and BCVA $0.15(0.08)$. The difference between the two groups was not significant at $P=0.57$ and $P=0.63$, respectively.
Preoperative assessment included standard ophthalmologic examination, UCVA, and BCVA. Visual acuity was measured using the Snellen's decimal chart, then converted to the logarithm of the minimum angle of resolution ( $\log$ MAR) for the purpose of statistical analysis. Cycloplegic and manifest refraction were performed. Topography was performed using Carl Zeiss Meditech Atlas ${ }^{\text {TM }}$ Version 2.0.0.34 and ultrasonic pachymetry was done using the Tomy Pachymeter SP-3000. Median central pachymetry for Group 1 was 535 (48) $\mu$ and for Group 2 was 534 (40) $\mu$. There was no statistical difference $(P=0.44)$ between the groups.

\section{Surgical technique}

The standard LASIK technique was used with no special modifications. Both eyes were operated at the same visit. The intended target of correction was emmetropia. To achieve this target we intentionally added +1.00 diopters to the intended correctable value. One eye was operated using an optical zone of $6.00 \mathrm{~mm}$, and the other eye of the same patient had an $6.5 \mathrm{~mm}$ optical zone. The Mel 80 Laser system (smart ablation profile and $0.75 \mathrm{~mm}$ flying spot, and frequency of $250 \mathrm{~Hz}$ ) and the Moria M2 microkeratome were used. We created a flap with a superior hinge, of average diameter $9.5 \mathrm{~mm}$, (range 9.3-9.8 depending on the ring used) and $90-\mu$ thickness. At the end of the procedure a bandage contact lens was applied.

\section{Postoperative care}

Postoperative medication was in the form of topical antibiotic and prednisolone $0.1 \%$ drops applied five times daily for one week, then tapered gradually over a four-day period. Topical lubricants were applied 4-6 times daily for six months. Patients were followed up on the same day of surgery (six hours later) to ensure the flap position and remove the contact lens. Postoperative visits were scheduled on days 1, 3 and 7, then every month for six months. At every visit a full ophthalmic examination was performed, and refraction and visual acuity (both UCVA and BCVA) were recorded. Operative complications including flap complications were noted. Postoperative complications such as inflammation, epithelial ingrowth, and regression were also recorded. Subjective patient complaints including haloes, glare, ghost images, and difficulties with night vision were also noted.

\section{Statistical analysis}

Parametric data were described as mean and standard deviation. Nonparametric data were described using the arithmetic mean 
À (range) for comparison of variables between two groups, using the Student $t$-test and Mann - Whitney $U$ test. All tests were two-tailed, and a $P$ value $<0.05$ was considered statistically significant. All statistical calculations were done using the SPSS (version 10.0; SPSS Inc., Chicago, IL) statistical program.

\section{Results}

The median postoperative UCVA in Group 1 (measured at the end of the six-month follow-up period) was 0.18 $(0.21)$ and BCVA was $0.15(0.13)$. In Group 2, the median postoperative UCVA was $0.30(0.32)$ and BCVA was 0.15 (0.26). In Group 1, the median postoperative refraction at one week was -0.23 (1.25) diopters, at three months was +0.75 (0.75) diopters, and at six months was +0.75 (1.00) diopters. In Group 2, the median postoperative refraction at one week was +0.13 (1.5), at three months was +1.00 (0.75) diopters, and at six months was +1.25 (1.25) diopters. The difference was statistically significant between groups 1 and 2 . The difference within each group was also significant, except that in Group 1 postoperative refraction between three and six months remained stable, whereas in Group 2 the refractive changes continued throughout the follow-up period (Table 1). The Figure shows the course of changes in refraction for the two groups, starting with the preoperative refraction and following up to six months postoperative refraction.

In Group 1, one eye (7.14\%) lost one line of BCVA due to flap microstriations not extending to the optical center. Meanwhile, three eyes (21.4\%) in Group 2 had lost one line of BCVA (Figure 1); one eye had epithelial ingrowth that induced astigmatism but did not necessitate any intervention, and the other two eyes had microstriations. One patient in Group 1 reported halos and glare (7.14\%). In Group 2, two patients reported halos and glare $(14.2 \%)$. Neither group had postoperative ectasia, infections, flap dislocations, or intraocular pressure elevations. Mild dry eye was present in almost all cases that improved in 3-6 months.

\section{Discussion}

Our study focused on the refractive outcome following LASIK in hyperopia of more than 4.00 diopters spherical equivalent, using a variable optical zone diameter $(6.50 \mathrm{~mm}$ and $6.00 \mathrm{~mm}$ ). The refractive outcome was evaluated for predictability, stability, and safety.

In this study predictability was assessed by the refraction at the end of the first week. In Group 1, 11 eyes (78.5\%) landed within \pm 0.50 diopters of the intended target and 14 eyes $(100 \%)$ landed within \pm 0.75 diopters. In Group 2, 10 eyes (71.4\%) landed within \pm 0.5 diopters of the intended target, 12 eyes (85.7\%) landed within \pm 0.75 diopters, and 14 eyes (100\%) within \pm 1.00 diopters. Ditzen et $\mathrm{al}^{3}$ reported $58 \%$ predictability in their group of above +4.00 diopters. Göker et al ${ }^{4}$ reported predictability of $81.48 \%$ in hyperopia between 4.00 and 8.00 diopters. Several other authors ${ }^{5}$ have reported predictability of up to $84 \%$ in hyperopia up to 17.00 diopters. This variation can be explained by the different ablation profiles, nomograms optical zone, and ablation zone diameter used by different investigators.

Stability of refraction was evaluated by refractive changes during the six-month follow-up period in both groups. In Group 1, the statistically significant changes in refraction were detected for up to three months. These changes were not significant between three and six months (see Table 1), whereas in Group 2 these changes were statistically significant up to the end of the follow-up period. Our results concerning regression are comparable with those of several other investigators ${ }^{2,6,7}$ who reported regression for up to 12 months postoperatively, which was influenced by and directly proportionate to the level of preoperative hyperopia and the magnitude of ablation. Kermani et $\mathrm{al}^{7}$ reported a mean 0.02 and 0.08 diopter regression over one year in a $6.5 \mathrm{~mm}$ and $7.0 \mathrm{~mm}$ optical zone diameter, respectively. Their results show more stability in comparison with ours, but this can be explained by the difference in preoperative hyperopia, which was higher in our series.

Table I Preoperative and postoperative refraction in the two groups

\begin{tabular}{lllll}
\hline & $\begin{array}{l}\text { Median (range) } \\
\text { preoperative } \\
\text { refraction SE } \\
\text { (diopters) }\end{array}$ & $\begin{array}{l}\text { Median (range) } \\
\text { postoperative } \\
\text { refraction one- } \\
\text { week SE (diopters) }\end{array}$ & $\begin{array}{l}\text { Median (range) } \\
\text { postoperative } \\
\text { refraction three } \\
\text { months SE (diopters) }\end{array}$ & $\begin{array}{l}\text { Median (range) } \\
\text { postoperative } \\
\text { refraction six months } \\
\text { SE (diopters) }\end{array}$ \\
\hline Group I & $5.37(1.75)$ & $-0.23(1.25)^{*}$ & $0.75(0.75)^{* \dagger}$ & $0.75(1.00)^{* \dagger}$ \\
Group 2 & $5.00(1.75)$ & $0.13(1.5)^{*}$ & $1.00(0.75)^{* \dagger}$ & $1.25(1.25)^{*+\neq}$ \\
\hline
\end{tabular}

Notes: *Significant difference compared with preoperative refraction SE; †Significant difference compared with postoperative refraction SE after one week; ${ }^{\prime}$ Significant difference compared with postoperative refraction SE after three months; **P obtained by Friedman rank test.

Abbreviation: SE, spherical equivalent. 


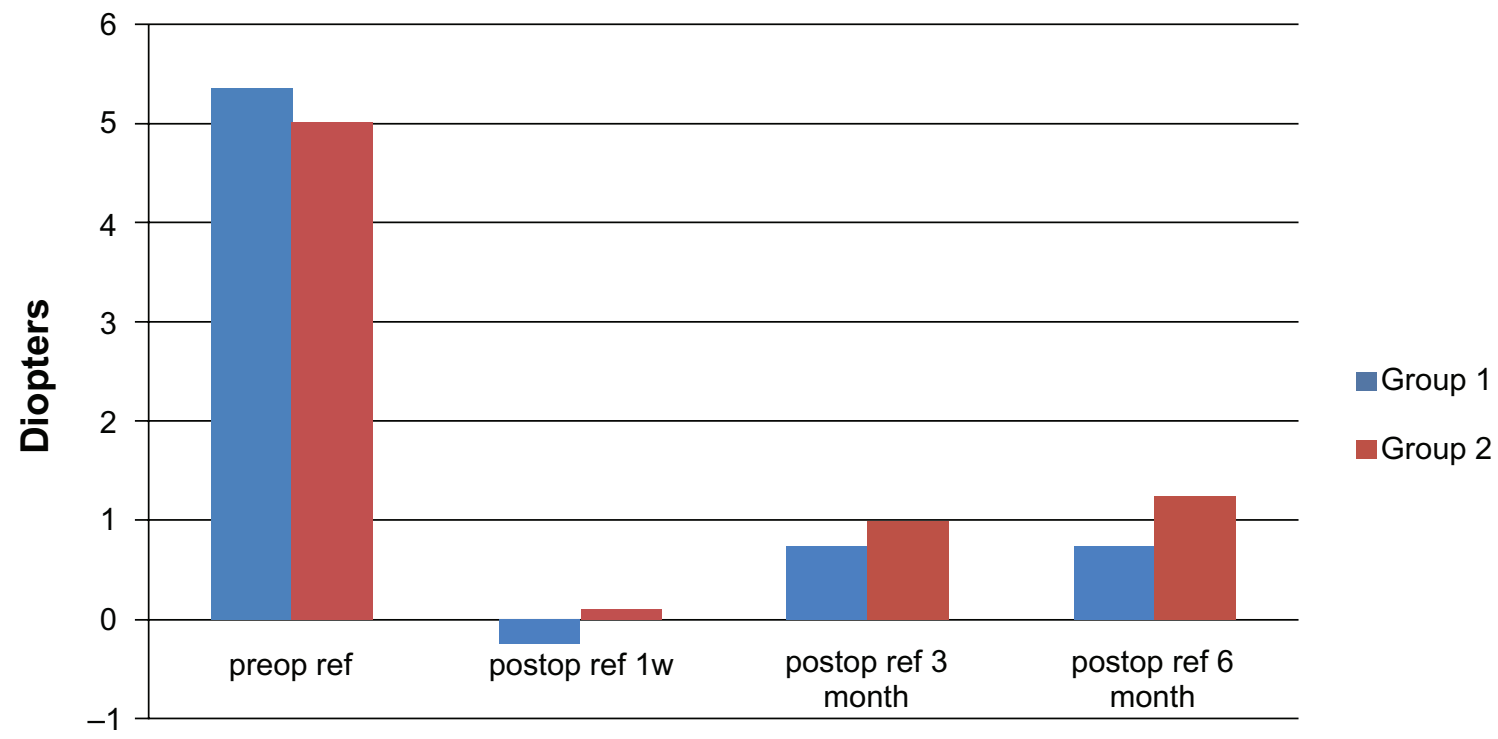

Time

Figure I Median preoperative and postoperative refractive changes in both groups throughout the follow-up period.

In our series, subjective patient complaints from haloes, glare, and ghost images in groups 1 and 2 were $7 \%$ and $14 \%$, respectively. This difference can be attributed to the larger optical zones in our series, ie, $6.5 \mathrm{~mm}$ and $6.0 \mathrm{~mm}$, and also due to the inclusion criteria in our study that helped to avoid a postoperative central keratometric value of more than 48.50 diopters. Increasing the optical zone diameter is more predictable and stable in correction of hyperopia between 4.00-6.00 diopters. However, a larger sample with a longer follow-up is recommended.

\section{Disclosure}

Neither author has any financial interest as a consultant, reviewer, shareholder, or evaluator in any of the products mentioned. No financial grants from public or private organizations were received to support this research.

Clinical Ophthalmology

\section{Publish your work in this journal}

Clinical Ophthalmology is an international, peer-reviewed journal covering all subspecialties within ophthalmology. Key topics include: Optometry; Visual science; Pharmacology and drug therapy in eye diseases; Basic Sciences; Primary and Secondary eye care; Patient Safety and Quality of Care Improvements. This journal is indexed on

Submit your manuscript here: http://www.dovepress.com/clinical-ophthalmology-journal

\section{References}

1. Cobo-Soriano R, Llovet F, Gonzalez-Lopez F, Domingo B, Gomez-Sanz F, Baviera J. Factors that influence outcomes of hyperopic laser in situ keratomileusis. J Cataract Refract Surg. 2002;28: $1530-1538$.

2. Davidorf JM, Eghbali F, Onclinx T, Maloney RK. Effect of varying the optical zone diameter on the results of hyperopic laser in situ keratomileusis. Ophthalmology. 2001;108:1261-1265.

3. Ditzen K, Huschka H, Pieger S. Laser in situ keratomileusis for hyperopia. J Cataract Refract Surg. 1998;24:42-47.

4. Göker S, Er H, Kahvecioglu C. Laser in situ keratomileusis to correct hyperopia from +4.25 to +8.00 diopters. J Refract Surg. 1998; 14 : 26-30.

5. Tabbara KF, El-Sheikh HF, Islam SM. Laser in situ keratomileusis for the correction of hyperopia from +0.50 to +11.50 diopters with the Keracor 117C laser. J Refract Surg. 2001;17:123-128.

6. Davidorf JM, Zaldivar R, Oscherow S. Results and complications of laser in situ keratomileusis by experienced surgeons. J Refract Surg. 1998; 14:114-122.

7. Kermani O, Schmeidt K, Oberheide U, Gerten G. Hyperopic laser in situ keratomileusis with 5.5-, 6.5-, and 7.0-mm optical zones. J Refract Surg. 2005;21:52-58.

\section{Dovepress}

PubMed Central and CAS, and is the official journal of The Society of Clinical Ophthalmology (SCO). The manuscript management system is completely online and includes a very quick and fair peer-review system, which is all easy to use. Visit http://www.dovepress.com/ testimonials.php to read real quotes from published authors. 